\section{SOI: 1.1/TAS DOI: 10.15863/TAS International Scientific Journal Theoretical \& Applied Science}

p-ISSN: 2308-4944 (print) e-ISSN: 2409-0085 (online)

Year: $2015 \quad$ Issue: $05 \quad$ Volume: 25

Published: $30.05 .2015 \quad$ http://T-Science.org
Denis Alexandrovich Chemezov

Master of Engineering and Technology, Corresponding member of International Academy of

Theoretical and Applied Sciences, Lecturer of Vladimir Industrial College, Russia chemezov-da@yandex.ru

Anzhelika Vladimirovna Bayakina Lecturer of Vladimir Industrial College, Russia bajakina.anzhelika@yandex.ru

Ekaterina Dmitrievna Bayakina Screenwriter, Studio City, CA, USA katebkn@gmail.com

\title{
SURFACE STRESS MODEL MADE OF Ti-6Al-4V ALLOY PROCESSED BY EQUAL CHANNEL ANGULAR PRESSING
}

\author{
Abstract: The article shows plots, $3 d$ contour graphs, of surface stress model made of Ti-6Al-4V alloy, \\ exposed to equal channel angular pressing, from $N$-normal resultant and M-moment resultant, operating on \\ different portions of a deformable material. \\ Key words: surface stress, equal channel angular pressing, $N$-normal resultant, $M$-moment resultant. \\ Language: English \\ Citation: Chemezov DA, Bayakina AV, Bayakina ED (2015) SURFACE STRESS MODEL MADE OF Ti- \\ 6Al-4V ALLOY PROCESSED BY EQUAL CHANNEL ANGULAR PRESSING. ISJ Theoretical \& Applied \\ Science 05 (25): 54-58. \\ Soi: http://s-o-i.org/1.1/TAS*05(25)11 Doi: rossef http://dx.doi.org/10.15863/TAS.2015.05.25.11
}

Increasing the strength, hardness and wear resistance of machine parts is achieved by hardening the surface layer of material (cold-hardening) by mechanical deformation or by other methods $[1,2]$. However, the plastic deformation process of the material becomes more difficult with the increase of the hardening of the surface layer.

Equal channel angular pressing (ECAP) is accompanied by the stresses emergence in various layers of deformable material. The intensity of surface stress characterizes the degree of hardening of the surface layer of the pressed material [3]. The intensity of the changing values (considering the sign - both positive and negative) of the surface stress is determined by the degree of deformation of the material. In areas of the pressed material model, which are in contact with the walls of the receiving and output channel of the matrix, deformation velocity and intensity are different. A force generated by the movement of the puncheon, directed parallel to the channel axis, is applied on a model which is laid in the receiving channel of the matrix. At the same time normal force applies causing displacement and deformation of the model material. Pressed model, while being punched from the receiving channel of the matrix to the output channel, changes the direction of displacement at a predetermined angle, there by bending moments occur. Moments are going to be positive or negative, depending on the direction of their action [4].

Analysis of the stress state of the surface layer of material from loads, on the example of Ti-6Al-4V alloy, allows to give recommendations on forecasting intensity of model hardening processed by ECAP.

The surface stress data is obtained by computer simulation of ECAP in the software environment LSDYNA.

Conditions for computer simulation performance: model made of Ti-6Al-4V alloy with outer diameter of $25 \mathrm{~mm}$ and $50 \mathrm{~mm}$ length, on the end surface of which $50 \mathrm{MPa}$ pressure was applied, was punched from the receiving channel of the matrix to the output channel at a $90^{\circ}$ angle over a time range of $16 \mathrm{~ms}$.

In the work [5] were determined the maximum values of the effective plastic strain $(\varepsilon=0.787)$, the resultant displacement $(\vec{s}=13.5 \mathrm{~mm})$, the resultant velocity $\left(v=1.525 \times 10^{3} \mathrm{~mm} / \mathrm{s}\right)$, the effective stress $\left(\sigma^{\prime}=275 \mathrm{MPa}\right)$ and the shear stress $(\tau=159 \mathrm{MPa})$ of the model material throughout the entire time range simulation of ECAP.

At $16 \mathrm{~ms}$ of the pressing process simulation the model takes the form shown on fig. 1. Four Selements (checkpoints) were chosen on solid threedimensional model, located close to the deformed model contact surfaces with the surfaces of the channels of the matrix, with the help of which 
calculated values of the simulation modeling were received. Calculations of the N-normal resultant, Mmoment resultant, and the surface stress of the model material were carried out throughout the entire time range of ECAP, with the $0.313 \mathrm{~ms}$ iteration step [6].

The surface stress of the material (values received from the coordinate axes and plane) can be defined by the equation (1):

$$
\Delta_{\tau_{S}}=\frac{1}{t}\left(N+\frac{6 M}{t}\right),
$$

where $\Delta \tau_{S}$ - surface stress of the material, $\mathrm{MPa} ; N$ $\left(N_{X}, N_{Y}, N_{X Y}\right)$ - normal resultant, N; $M\left(M_{X}, M_{Y}, M_{X Y}\right)$ - moment resultant, $\mathrm{N} \times \mathrm{mm} ; t$ - time, $\mathrm{ms}$.

The results of the computer simulation realization were statistically processed (DistanceWeighted Least Squares Fitting method) [7, 8]. 3d contour graphs [9] of surface stress dependence of the model material were built from $N_{X^{-}}, N_{Y^{-}}, N_{X Y^{-}}$ normal resultant and $M_{X^{-}}, M_{Y^{-}}, M_{X Y^{-}}$moment resultant at $1-4$ checkpoints during the time of angular pressing (fig. $2-4$ ).

On the graphs the abscissa axis represents $\mathrm{N}$ normal resultant values, the axis of ordinates - Mmoment resultant. The color palette of graphic (the third coordinate axis) represents the surface stress of the model material values. The intervals of the surface stress values are determined by the similar colors in rectangles placed in the right bottom corner near the interactive graphs of dependencies.

Let's consider the graphics on fig. $2, \mathrm{a}-\mathrm{d}$. The nature of changes of the surface stress of the material at the 1 st and the 4th checkpoints is almost the same throughout the entire time range. However, at the first point predominantly negative values of $\mathrm{N}_{X^{-}}$ normal resultant and $\mathrm{M}_{\mathrm{X}}$-moment resultant are observed, and at the fourth - positive values. At the second checkpoint, located on the border of the inner pair of the receiving and output channels of the matrix, both positive and negative values of $\mathrm{N}_{\mathrm{X}^{-}}$ normal resultant and $\mathrm{M}_{\mathrm{X}}$-moment resultant were registered in the $-150 \ldots 250 \mathrm{~N}$ and $-80 \ldots 40 \mathrm{~N} \times \mathrm{mm}$ ranges respectively. Characteristic change of parameters occurs in the third checkpoint too, but the value of the surface stress will be less than at point 2 . Thus, it is determined that among the considered checkpoints the maximum surface stress value $(-340$ $\mathrm{MPa}$ ) on the $X$ coordinate axis occurs in the area associated with the checkpoint 2, where the greatest hardening of the pressed material takes place.
$\mathrm{N}_{Y}$-normal resultant has negative values throughout the entire time range, $\mathrm{M}_{\mathrm{Y}}$-moment resultant - positive and negative values (fig. $3, a-b$ ). The surface stress of the material of -540 MPa value (checkpoint 2) occurs under the simultaneous influence of negative $\mathrm{N}_{\mathrm{Y}}$-normal resultant $(-280 \mathrm{~N})$

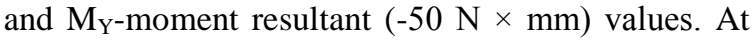
the checkpoints 3 and 4 (fig. 3, c - d) significant quantities of $\mathrm{N}_{\mathrm{Y}}$-normal resultant with a plus sign operate. At point $3 \mathrm{~N}_{\mathrm{Y} \text {-normal resultant values }}$ reaches $200 \mathrm{~N}$, and as punching of the material continues an increase of the parameter to $300 \mathrm{~N}$ values (point 4) is observed.

On the $X Y$ plane the values of $\mathrm{N}_{\mathrm{XY}}$-normal resultant and $\mathrm{M}_{\mathrm{XY}}$-moment resultant are minimal, and they do not exceed $8--12 \mathrm{~N}$ for force and $20-$ $140 \mathrm{~N} \times \mathrm{mm}$ for moment at the checkpoints $1-4$ (fig. $4, \mathrm{a}-\mathrm{d}$ ). The maximum value of surface stress of the material is $-148 \mathrm{MPa}$.

By results of research of angular pressing process of the model made of $\mathrm{Ti}-6 \mathrm{Al}-4 \mathrm{~V}$ alloy following conclusions were made:

1. The mechanism of surface hardening of the model is represented by different stages of deformation of the material at the control points: a the action of $\mathrm{N}$-normal resultant (negative parameter values are caused by the resistance force of the material under a pressure on the bottom wall of the output matrix channel) in the receiving channel (point 1); b - an increase of $\mathrm{N}$-normal resultant and M-moment resultant values (negative parameter values - clockwise action) in the area of the inner pair of the receiving and output channels (point 2); c - the decrease of M-moment resultant values at an invariable value of $\mathrm{N}$-normal resultant as a result of further model displacement in the output channel (points 3 and 4).

2. The simultaneous action of negative Nnormal resultant values and positive M-moment resultant (e.g., fig. 3, b) leads to the emergence of surface stress with positive values. Thus, the positive or negative values of the surface stress of the material will be significantly affected by the matching sign M-moment resultant values.

3. The residual surface stress of the model at the checkpoint 4 reaches $200 \mathrm{MPa}$ value, which corresponds to a high degree of hardening of the surface layer material. 


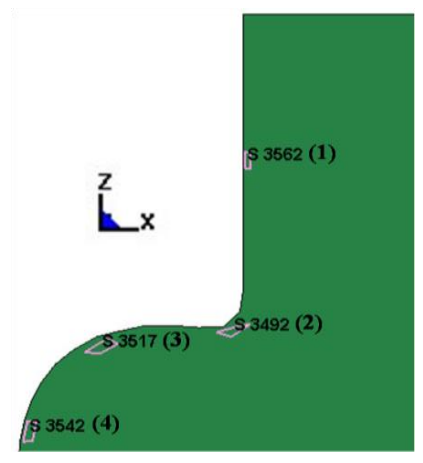

Figure 1 - The final layout of checkpoints 1 - 4, in which M-moment resultant values, N-normal resultant values and surface stress values were obtained on the material of the model processed by ECAP.

a)
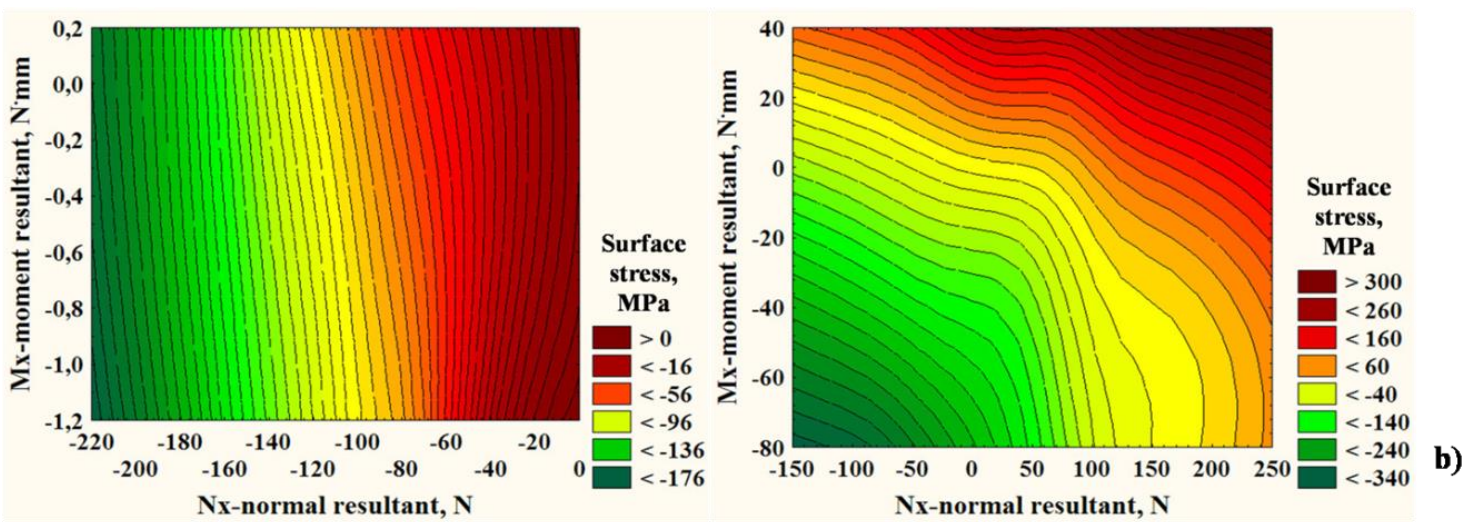

c)
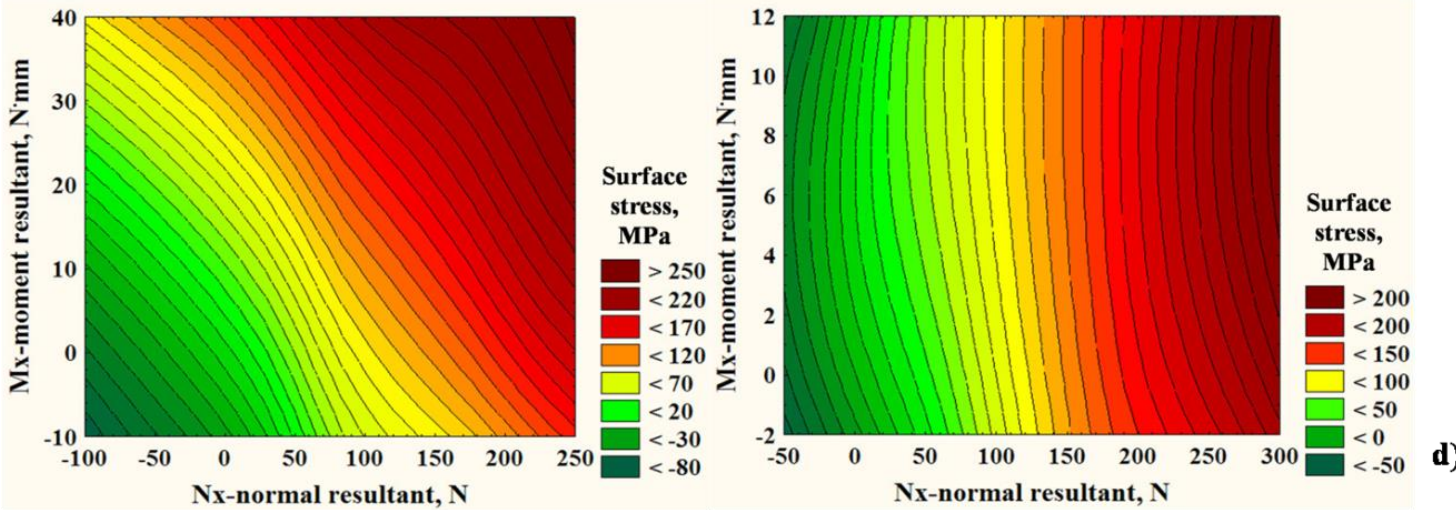

Figure 2 - The dependences of the surface stress of the model material from $\mathrm{Nx}$-normal resultant and Mx-moment resultant throughout the pressing time: a - element 3562 (checkpoint 1, fig. 1); b - element 3492 (checkpoint 2); c - element 3517 (checkpoint 3); d - element 3542 (checkpoint 4). 
a)

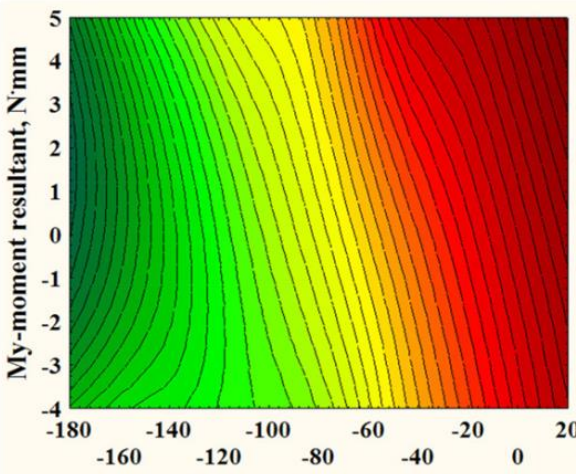

Ny-normal resultant, $N$

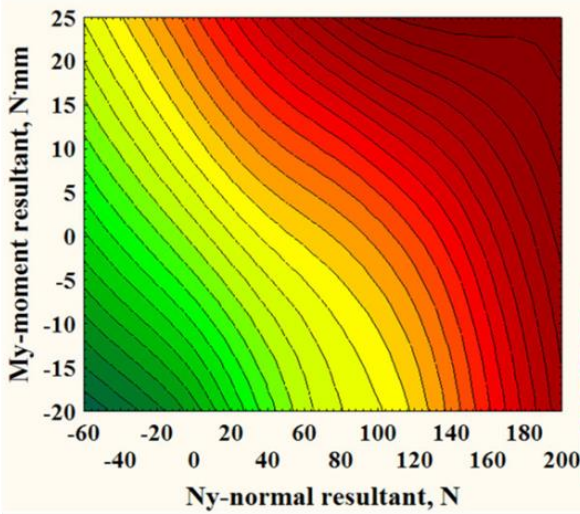

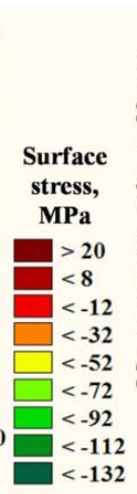
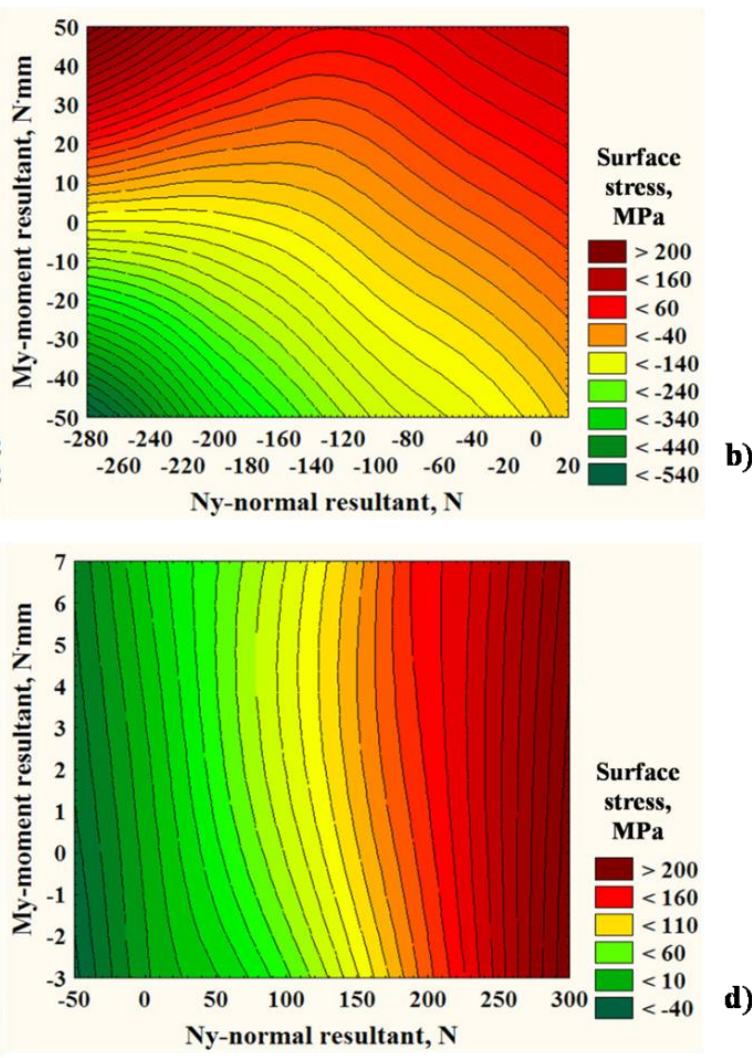

Figure 3 - The dependences of the surface stress of the model material from Ny-normal resultant and My-moment resultant throughout the pressing time: a - element 3562 (checkpoint 1, fig. 1); b - element 3492 (checkpoint 2); c - element 3517 (checkpoint 3); d - element 3542 (checkpoint 4).

a)

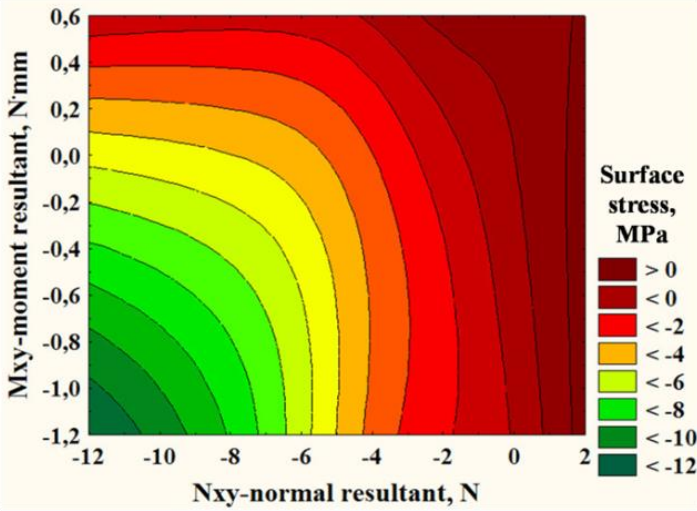

c)

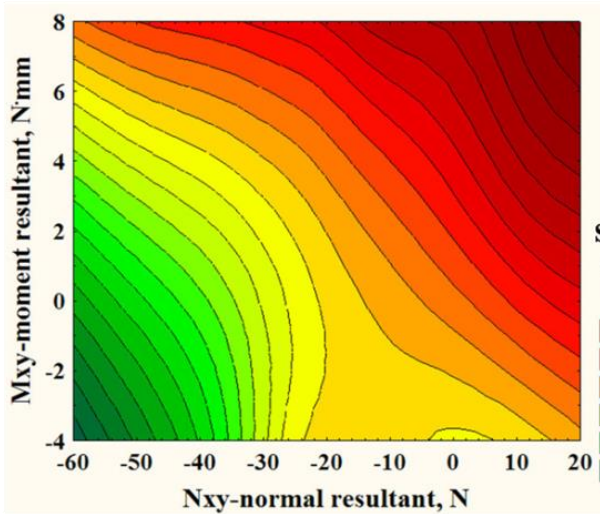

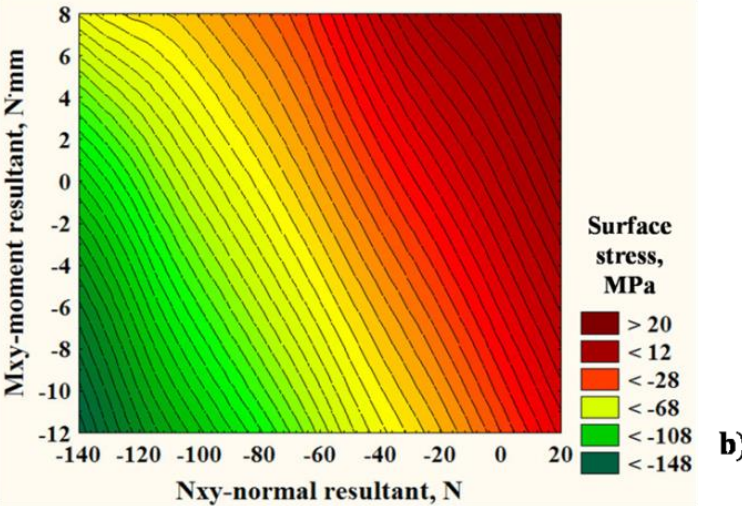

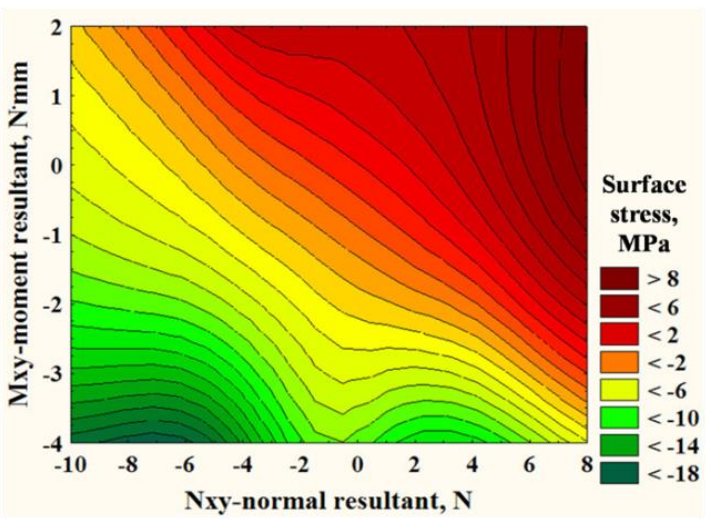

Figure 4 - The dependences of the surface stress of the model material from Nxy-normal resultant and Mxy-moment resultant throughout the pressing time: a - element 3562 (checkpoint 1, fig. 1); b - element 3492 (checkpoint 2); c - element 3517 (checkpoint 3); d - element 3542 (checkpoint 4).

ISPC Industry \& Technology Europe,

Lyon, France 


\section{References:}

1. (2015) Naklep. Available: https://ru.wikipedia.org/wiki/\%CD\%E0\%EA\% EB\%B8\%EF (Accessed: 13.05.2015).

2. (2015) Mehanizm deformacii i uprochneniya metallov. Available: http://mashxxl.info/info/511552/ (Accessed: 13.05.2015).

3. (2015) Uprochnenie poverhnostnym plasticheskim deformirovaniem. Available: http://tehnoinfo.ru/tehnolog/mashstroy/293plastich-diform.html (Accessed: 13.05.2015).

4. (2015) Pravilo znakov. Available: http://sopromat.in.ua/textbook/sign-convention (Accessed: 13.05.2015).

5. Chemezov DA, Bayakina AV (2015) The intensity of stress \& strain of the model, which is made of titanium alloy $\mathrm{Ti}-6 \mathrm{Al}-4 \mathrm{~V}$, during equal channel angular pressing. ISJ Theoretical \& Applied Science 04 (24): 74-79. Soi: http://so-i.org/1.1/TAS*04(24)13 Doi: http://dx.doi.org/10.15863/TAS.2015.04.24.13
6. (2015) Iteraciya. Available: http://btimes.ru/dictionary/iteratsiya (Accessed: 13.05.2015).

7. (2015) Metody obrabotki rezultatov experimenta. Available: http://old.iro.yar.ru/resource/distant/pedagogy/p edagogicheskii_eksperement/basov/sekret/etap1 $\underline{1 . h t m l}$ (Accessed: 13.05.2015).

8. (2015) Distance-Weighted Least Squares Fitting. Available: http://documentation.statsoft.com/STATISTIC AHelp.aspx?path=Graphs/Graph/ModifyingGra phs/Notes/DistanceWeightedLeastSquaresFittin g (Accessed: 13.05.2015).

9. (2015) Graficheskie instrumenty STATISTICA. Available:

http://www.statsoft.ru/products/overview/graph s.php (Accessed: 13.05.2015). 